\title{
Microspheres: as carrieres used for novel drug delivery system
}

\author{
Ramteke K.H ${ }^{1}$, Jadhav V.B ${ }^{2}$, Dhole S.N. ${ }^{3}$ \\ Modern College of Pharmacy (For Ladies), Moshi, Pune 412508, Maharashtra State, India.
}

\begin{abstract}
The goal of any drug delivery system is to provide a therapeutic amount of drug to the proper site in the body and then maintain the desired drug concentration. A well designed controlled drug delivery system can overcome some of problems of conventional therapy and enhance therapeutic efficacy of the given drug. There are various approaches in delivering therapeutic substance to the target site in sustained and controlled release fashion. One such approach is using microspheres as carriers for drug. Microspheres are characteristically free flowing powders consisting of proteins or synthetic polymers which are biodegradable in nature ideally having particle size less than $200 \mu \mathrm{m}$.Various synthetic and natural materials are used for the preparation of microspheres. These are prepared by methods like Single emulsion, Double emulsion, Polymerization, Phase separation coacervation, Emulsion solvent evaporation and solvent diffusion. Microspheres are having wide range of applications because of controlled and sustained release. Most important application is that it is used for targeting tumours using anticancer drugs. It is important carrier for safe and effective in vivo drug delivery.
\end{abstract}

Keywords-Microspheres, Characterization of microspheres, Controlled release, Target site, Specificity, Therapeutic efficacy, Novel drug delivery.

\section{INTRODUCTION}

Microspheres are characteristically free flowing powders consisting of proteins or synthetic polymers, which are biodegradable in nature and ideally having a particle size less than $200 \mu \mathrm{m}$. This is the important approach in delivering therapeutic substance to the target site in sustained and controlled release fashion. ${ }^{(1)}$

\subsection{Advantages of Microspheres ${ }^{(2)}$}

They facilitate accurate delivery of small quantities of potent drug and reduced concentration of drug at site other than the target organ or tissue.

They provide protection for unstable drug before and after administration, prior to their availability at the site of action.

They provide the ability to manipulate the in vivo action of the drug, pharmacokinetic profile, tissue distribution and cellular interaction of the drug. They enable controlled release of drug. Examples: Narcotic, Antagonist, Steroid hormones

Materials used ${ }^{(1)(3)}$ : Microspheres used usually are polymers. They are classified into two types

1. Synthetic polymers

2. Natural polymers

2.1 Synthetic polymers

Nonbiodegradable polymers: Polymethyl methacrylate (PMMA), Acrolein, Glycidyl

methacrylate, Epoxy polymers

Biodegradable polymers: Lactides, their glycolides and their copolymers, Polyalkyl

Cyano Acrylate, Polyanhydrides

\subsection{Natural polymers}

These are obtained from different sources like proteins, carbohydrates and chemically modified carbohydrates.

Proteins: Albumin, Gelatin, And Collagen, Carbohydrates: Agarose, Carrageenan, Chitosan, Starch, Chemically Modified Carbohydrates: Poly (acryl) dextran, Poly (acryl) starch

\section{Types of Microspheres}

3.1 Bioadhesive Microspheres ${ }^{(4)(5)(6)}$ : These kinds of microspheres exhibit a prolonged residence time at the site of application and causes intimate contact with the absorption site and produces better therapeutic action.

3.2 Magnetic Microspheres ${ }^{(4)(7)}$ : Magnetic microspheres are supramolecular particles that are small enough to circulate through capillaries without producing embolic occlusion $(<4 \mu \mathrm{m})$ but are sufficiently succeptible 
(ferromagnetic)to be captured in microvessels and dragged into the adjuscent tissues by magnetic field of 0.50.8 tesla.

3.3 Floating Microspheres ${ }^{(4)(8)(9)}$ : Gastro-retentive floating microspheres are low-density systems that have sufficient buoyancy to float over gastric contents and remain in stomach for prolonged period without affecting gastric emptying rate. The drug is released slowly at the desired rate.

3.4 Radioactive Microspheres ${ }^{(4)(10)}$ : Radioactive microspheres deliver high radiation dose to the targeted areas without damaging the normal surrounding tissues. They are injected to the arteries that lead to tumour of interest. The different kinds of radioactive microspheres are $\alpha$ emitters, $\beta$ emitters and $\gamma$ emitters.

3.5 Polymeric Microspheres ${ }^{(4)}$ : Biodegradable polymeric microspheres are those which contain biodegradable polymers which prolongs the residence time when contact with mucous membrane due to it's high degree of swelling property with aqueous medium, results gel formation. The rate and extent of drug release is controlled by concentration of polymer and the release pattern in a sustained manner. Synthetic polymeric microspheres are those which are made up of synthetic polymers and are used as used as bulking agent, fillers, embolic particles, drug delivery vehicles etc.

\section{METHODS}

4.1 Single emulsion technique ${ }^{(1)(3)(4)}$ : The microparticulate carriers of natural polymers i.e. those of proteins and carbohydrates are prepared by single emulsion technique.The natural polymers are dissolved/dispersed in aqueous medium followed by dispersion in the non-aqueous medium e.g. oil. In the second step of preparation, cross-linking of dispersed globule is carried out. The cross linking is achieved by two methods i.e. either by heat or by means of chemical cross linking agents including glutaraldehyde, formaldehyde, diacid chloride etc.

4.2 Double emulsion technique ${ }^{(1)(3)(4)(11)}$ : This method involves the formation of the multiple emulsion or double emulsion of type w/o/w. It is best suited to water soluble drugs, peptides, proteins and vaccines. This method can be used with both the natural as well as the synthetic polymers. The aqueous protein solution is dispersed in a lipophilic organic continuous phase .This protein solution may contain the active constituents. The continuous phase is generally consisted of the polymer solution that eventually encapsulates of the protein contained in dispersed aqueous phase. The primary emulsion is then subjected to the homogenisation or the sonication before addition to the aqueous solution of the poly vinyl alcohol (PVA). This results in formation of a double emulsion. Emulsion is then subjected to solvent removal either by solvent evaporation or by solvent extraction process. The solvent evaporation is carried out by maintaining emulsion at reduced pressure or by stirring the emulsion so that the organic phase evaporates out. The emulsion is then added to large quantity of water into which organic phase diffuses out. The solid microspheres are subsequently obtained by filtration and washing with n-hexane, acetone or any organic solvent to remove traces of oil from the surface.

4.3 Polymerization ${ }^{(1)(3)(4)(12)}$ : The polymerisation techniques conventionally used for the preparation of the microspheres, are mainly classified as:

\section{Normal polymerisation}

\section{Interfacial polymerisation}

\subsubsection{Normal polymerization ${ }^{(13)}$ -}

Normal polymerisation proceeds and is carried out using different techniques as bulk, suspension precipitation, emulsion and micellar polymerisation processes. In bulk polymerisation, a monomer or a mixture of monomers along with the initiator or catalyst is usually heated to initiate polymerization. Polymer so obtained may be moulded as microspheres. Drug loading may be done during the process of polymerization. Suspension polymerization also referred as bead or pearl polymerization. Here it is carried out by heating the monomer or mixture of monomers as droplets dispersion in a continuous aqueous phase. The droplets may also contain an initiator and other additives. Emulsion polymerization differs from suspension polymerization as due to the presence initiator in the aqueous phase, which later on diffuses to the surface of micelles. Bulk polymerization has an advantage of formation of pure polymers.

\subsubsection{Interfacial polymerization ${ }^{(1)}$ :}

It involves the reaction of various monomers at the interface between the two immiscible liquid phases to form a film of polymer that essentially envelops the dispersed phase. In this technique two reacting monomers are employed, one of which is dissolved in the continuous phase while the other being dispersed in the continuous phase.

4.4 Phase separation/ Coacervation (1) (3) (14): Phase separation method is mainly designed for preparing the reservoir type of the system. This method is used to encapsulate water soluble drugs e.g. peptides, proteins and some of preparations having matrix type particular, when the drug is hydrophobic in nature e.g. steroids. In this technique the polymer is first dissolved in a suitable solvent and then drug is dispersed by making its aqueous 
solution, if hydrophobic or dissolved in polymer solution itself, If hydrophobic. Phase separation is then accomplished by changing the solution conditions by the salt addition, on-solvent addition, addition of the incompatible polymer or change in $\mathrm{P}^{\mathrm{H}}$

4.5 Spray drying ${ }^{(1)}{ }^{(3)}{ }^{(15)}$ : The polymer is first dissolved in a suitable volatile organic solvent such as dichloromethane, acetone etc. The drug in the solid form is then dispersed in the polymer solution under high speed homogenisation. This dispersion is then atomised in a stream of hot air. The atomisation leads to the formation of small droplets or the fine mist from which the solvent evaporates instantaneously leading the formation of microspheres.

4.6 Solvent extraction ${ }^{(1)}$ : Solvent extraction method is used for the preparation of the micro particles, involves removal of the organic phase by extraction of the organic solvent. The method involves water miscible organic solvents such as isopropanol. Organic phase is removed by extraction with water. This process decreases the hardening time for the microspheres. The process involves direct addition of the drug or protein to polymer organic solution. The rate of solvent removal by extraction method depends on the temperature of water, ratio of emulsion volume to the water and the solubility profile of the polymer.

4.7 Emulsion Solvent Evaporation ${ }^{(1)(3)(16)(17)}$ : In this technique the drug is dissolved in polymer which was previously dissolved in chloroform and the resulting solution is added to aqueous phase containing $0.2 \%$ sodium of PVP as emulsifying agent. The above mixture was agitated at $500 \mathrm{rpm}$ then the drug and polymer (eudragit) was transformed into fine droplet which solidified into rigid microspheres by solvent evaporation and then collected by filtration and washed with demineralised water and desiccated at room temperature for $24 \mathrm{hrs}$. 4.8 Emulsion solvent diffusion technique ${ }^{(1)}{ }^{(3)}{ }^{(18)}$ : The colon floating microspheres were prepared using emulsion solvent diffusion technique in order to improve the residence time. The drug polymer mixture was dissolved in a mixture of ethanol and dichloromethane (1:1) and then the mixture was added dropwise to sodium lauryl sulphate (SLS) solution. The solution was stirred with propeller type agitator at room temperature at 150 $\mathrm{rpm}$ for $1 \mathrm{hr}$. Thus the formed floating microspheres were washed and dried in a dessicator at room temperature.

\section{Physicochemical characterization and evaluation ${ }^{(1)(3)(4)}$}

1. Particle size and shape: Laser microscopy, Scanning electron microscopy

2. Electron spectroscopy for chemical analysis: Determines surface chemistry

3. Attenuated total reflectance Fourier Transfom-Infrared Spectroscopy: Determines degradation of polymeric matrix

4. Capture efficiency: \% Entrapment $=$ Actual content/Theoretical content $\mathrm{x} 100$

5. Thermal analysis: Differential Scanning Calorimetry (DSC)

6. Swelling index: Characterization of microspheres is performed with swelling index technique. Different solution $(100 \mathrm{~mL})$ are taken such as (distilled water, buffer solution of $\mathrm{pH}(1.2,4.5,7.4)$ are taken and alginate microspheres $(100 \mathrm{mg}$ ) are to be placed in a wire basket and kept on the above solution and swelling is allowed at $37^{\circ} \mathrm{C}$ and changes in weight variation between initial weight of microspheres and weight due to swelling was measured by taking weight periodically and soaking with filter paper.

Swelling Index $=$ Initial weight - Final weight/ Initial weight $\times 100$

7. Floating behaviour: Fifty milligrams of the floating microspheres are placed in $100 \mathrm{ml}$ of the simulated gastric fluid (SGF, pH 2.0) containing $0.02 \% \mathrm{w} / \mathrm{v}$ Tween 20 . The mixture is stirred at $100 \mathrm{rpm}$ with a magnetic stirrer. After 8 hours, the layer of buoyant microspheres is pipetted and separated by filtration. Particles in the sinking particulate layer are separated by filtration. Particles of both types are dried in a desiccator until constant weight is achieved. Both the fractions of microspheres weighed and buoyancy is determined by the weight ratio of floating particles to the sum of floating and sinking particles.

a. Buoyancy $(\%)=\mathrm{Wf} / \mathrm{Wf}+\mathrm{Ws}$

i. Where, Wf and Ws are the weights of the floating and settled microparticles.

8. Micromeritic properties such as tapped density, bulk density, compressibility index, angle of repose are also studied.

9. Release studies for different type of microspheres are carried out by using different suitable dissolution media, mostly by rotating paddle apparatus (USP / BP).The speed of rotation varies from 50-100 rpm. The samples are taken at a specific time interval and replaced by same amount of dissolution medium. The active ingredient withdrawn in the sample is analysed as per monograph requirement and release profile is determined by using the plot amount released as a function of time. Dialysis and Franz diffusion cell technique is also used. 
10. Isoelectric point, Surface carboxylic acid residue, Surface amino acid residue are also studied.

\section{APPLICATIONS ${ }^{(3)(4)}$ :}

\begin{tabular}{|c|c|}
\hline Type of microspheres & Applications \\
\hline Bioadhesive microspheres & $\begin{array}{l}\text { Buccal, oral, ocular, nasal, colonic drug delivery } \\
\text { Nasal - Gentamicin, Insulin }{ }^{(19)}, \text { GI - Glipizide }{ }^{(20)} \\
\text { Colonic - Insulin }^{(21)} \\
\text { Ocular - Methyl prednisolone }^{(22)}\end{array}$ \\
\hline Magnetic microspheres & $\begin{array}{l}\text { Used in DNA analysis, cell isolation, protein purification and targetting drugs } \\
\text { to tumour sites( Doxorubicin) })^{(4)(7)}\end{array}$ \\
\hline Floating microspheres & $\begin{array}{l}\text { Carriers for drugs like antiviral, antifungal and antibiotic agents(so called } \\
\text { absorption windows), non-steroidal anti inflammatory drugs, Prednisolone, } \\
\text { Lansoprazole }(4)(8)(23)\end{array}$ \\
\hline Radioactive microspheres & $\begin{array}{l}\text { For diagnostic purpose - Diagnostic radioembolization: }{ }^{99 \mathrm{~m}} \text { Tc-macro- } \\
\text { aggregated human serum albumin (MAA) }{ }^{(24)} \text {, Thrombus imaging in deep vein } \\
\text { thrombosis : }{ }^{99} \mathrm{mTc} \text {-sulfur colloid }{ }^{(25)} \\
\text { For therapeutic purpose - Radioembolization of liver and spleen tumours: }{ }^{90} \mathrm{Y}- \\
\text { microspheres }{ }^{(26)} \text {, Local radiotherapy: }{ }^{212} \mathrm{~Pb} \text {-sulfur colloid }{ }^{(26)} \text {. }\end{array}$ \\
\hline Polymeric microspheres & $\begin{array}{l}\text { Vaccine delivery: Hepatitis, Influenza, Pertussis, Diptheria toxoid }{ }^{(4)(10)} \text {, Oral } \\
\text { drug delivery of easily degraded drugs: Gene therapy with DNA plasmids; } \\
\text { delivery of insulin, LHRH } \\
\text { Controlled drug delivery after local application : Release of proteins, hormones } \\
\text { and peptides over extended times }\end{array}$ \\
\hline
\end{tabular}




\section{CONCLUSION}

Microsphere is a short term but it is having wide applications in drug delivery systems. Most important are the targeted drug delivery (Bioadhesive microspheres-nasal, ocular, buccal, rectal etc., Magnetic microspheres and Radioactive micospheres - For tumours), Controlled and sustained drug delivery (Polymeric microspheres, Floating microspheres). By combining various strategies, microspheres will find central place in novel drug delivery mainly particularly in cell sorting, diagnostics and Genetic engineering. From the study it is proved that Microspheres act as effective carriers for the novel drug delivery system.

\section{REFERENCE}

[1]. Vyas and Khar. Targeted and Controlled drug delivery (CBS Publishers and distributors, 2001).

[2]. T. Omkar, M. Alagusundaram, S.C. Madhu, K. Umashankari, V.B. Attuluri, C. Lavanya, B. Ramkanth, Microspheres as a novel drug delivery system, Int J Of Chem Tech and Res, 3(1),2009,526-534.

[3]. N.R. Patel, D.A. Patel, P.D Bharadia, V. Pandya, V. Modi, Microsphere as a novel drug deliver, Int J of Pharm \& Life Sci, 2(8),2011,992-997.

[4]. V.V. Prasanth, A.C. Moy, S.T. Mathew, R. Mathapan, Microspheres: an overview, Int J of Pharm \& Biomedical Sci, 2(2),2011,332-338

[5]. J.K. Vasir, K. Tambekar, Bioadhesive microspheres as a controlled drug delivery system, Int J Pharm, 255, 2003, 13-32.

[6]. A. Senthil, V.B. Narayanswamy, D.S. Galge, R.S. Bhosale, Mucoadhesive microspheres, IJRAP,2(1),2011,55-59.

[7]. P. Chandrawanshi, H. Patidar, Magnetic microspheres: as a targeted drug delivery, J of Pharm Res, 2(5), 2009, 964-966.

[8]. C. Chawla, P. Gupta, V. Karadia, A.K. Bansal, Gastroretention - A means to address regional variability in intestinal drug absorption, Pharm Tech ,27(2),2003,50-68.

[9]. S.P. Gholap, S.K. Banrjee, D.D Gaikwad, S.L. Jadhav, R.M. Thorat, Hollow microspheres: A Review, Int J of Pharm Sci Review and Res ,1(1),2010,74-79.

[10]. U. Hafeli, R.W. Atcher, C.E. Morris, B. Beresford, J.L. Humm, R.M. Macklis, Polymeric radiopharmaceutical delivery systems, Radioactivity \& Radiochemistry, 3, 1992,11-14

[11]. D. Jain, A.K. Panda, D.K. Majumdar, Eudragit S100 Entrapped Insulin Microspheres for Oral Delivery, AAPS Pharm Sci Tech, 6 (1), 2005, 101-107.

[12]. G.B. Chinna, S.R. Shyam, K.M. Vimal, R.M. Sleeva, K.M. Sai, Formulation and Evaluation of Indomethacin Microspheres using natural and synthetic polymers as Controlled Release Dosage Forms, Int J of Drug Discovery ,2(1),2010,8-16.

[13]. W.Q. Zhou, T.Y Gu, Z.G Su, G.H. Ma, Syntheses of macroporous poly (styrene-divinyl benzene) microspheres by surfactant reverse micelles swelling method, Science Direct Polymer,48,2007,1981-1988.

[14]. S. Sunitha , P. Amareshwar , K.M. Santhosh, P. Chakravarti , Preparation and Evaluation of Tramadol Hydrochloride microspheres by phase separation coacervation technique using various solvents and nonsolvents, J of Global Pharm Tech,3(4),2011,33-41.

[15]. H. Mahajan, S. Gattani, S. Surana, Spray Dried Mucoadhesive Microspheres of Ondansetron for Nasal Administration, Int J of Pharma Sci and Nanotech, 1(3), 2008, 267-273.

[16]. P. Venkatesan, R. Manavalan, K. Valliappan, Preparation and evaluation of sustained release loxoprofen, $J$ of Basic and Clinical Pharmacy,2(3),2011,159-162.

[17]. P.S. Lakshmana, A. Shirwaikar, A. Kumar, Formulation and evaluation of sustained release microspheres of rosin containing aceclofenac, Ars Pharm,50(2),2009,51-62.

[18]. M.K. Das, K.R. Rao, Evaluation of Zidovudine encapsulated ethylcellulose microspheres prepared by Water-Oil-Water double emulsion solvent diffusion technique, Acta Poloniae Pharmaceutica \& Drug Research ,63(2),2006, $141-148$.

[19]. N.F. Farraj, B.R. Johansen, S.S. Davis, L. Illum, Nasal administration of insulin using bioadhesive microspheres as a drug delivery system, J Control Release ,80,1990,161-169.

[20]. K. Kyyronen, L. Hume, C. Benedict, A. Urtti, E. Topp, V. Stell, Methyl prednisolone esters of Hyluronic acid in opthalmic drug delivery in vitro and in-vivo release studies, Int J Pharm,49,1992,732-792.

[21]. S. Geary, S.W. Schalamens, Vancomycin and Insulin used as models for oral delivery of peptides, J Control Release, 46,1993,661-665.

[22]. J.K. Patel, A.F. Amin, M.M. Patel, Formulation, Optimization and Evaluation of controlled release mucoadhesive microspheres of glipizide for oral drug delivery using factorial design, Drug Delivery Tech,4,2004, 48-53.

[23]. A.A. Shirwalkar, S.M. Kumar, S. Jacob, Recent developments in floating drug delivery systems for gastric retention of drugs: An overview, Indian drugs. 43 (9), 2006, 697-704.

[24]. M.T. Ercan, Rapid determination of hydrolysed-reduced Technetium-99m in particulate radiopharmaceuticals, Appl Radiat Isot - Int J Radiat Appl Instrum Part A 43, 1992, 1175-1177.

[25]. L. Knight, Thrombus-localizing radiopharmaceuticals, In Fritz berg AR (Ed.). Radiopharmaceuticals: Progress and clinical perspectives, CRC Press, Boca Raton, Florida, 1986, 23-40.

[26]. J.L. Russell, J.L. Carden, L. Herron, Dosimetry calculations for Yttrium-90 used in the treatment of liver cancer, Endocurietherapy/Hyperthermia Oncology,4,1988, 171-186 